\title{
Does Technological Innovation Improve the Regional Ecological Efficiency? Empirical Evidence From China
}

\section{Huan Huang}

Chengdu University of Technology

Jiaxin Kuang

Chengdu University of Technology

Fan Wang

Chengdu University of Technology

Ke Tian

Chengdu University of Technology

Yi Xiao ( 0 505649708@qq.com )

Chengdu University of Technology

\section{Research Article}

Keywords: Technological innovation, Ecological efficiency, Spatial econometric models, China

Posted Date: August 24th, 2021

DOI: https://doi.org/10.21203/rs.3.rs-777838/v1

License: (c) (i) This work is licensed under a Creative Commons Attribution 4.0 International License. Read Full License 


\section{Title page}

\section{Huan Huang}

4 College of business, Chengdu University of Technology, Chengdu,

5 Sichuan, 610059, China

6 Email: huan@,cdut.edu.cn

7

8

\section{Jiaxin Kuang}

9 College of business, Chengdu University of Technology, Chengdu,

10 Sichuan, 610059, China

11 Email: 2645989027@qq.com

14 College of business, Chengdu University of Technology, Chengdu,

15 Sichuan, 610059, China

16 Email: 18428355417@,163.com

19 College of tourism and urban-rural planning, Chengdu University of

20 Technology, Chengdu, Sichuan, 610059, China

21 Email: tiankk0525@163.com 
24 College of management science, Chengdu University of Technology,

25 Chengdu, Sichuan, 610059, China

26 Email: benbenyi93@163.com

27

28 Declarations of interest: None. 


\section{Does technological innovation improve the} regional ecological efficiency? Empirical evidence from China

\section{Abstract}

The rapid development of China's economy and urbanization has led to the rapid deterioration of the ecological environment. This study aims to explore the relationship between provincial eco-efficiency and technological innovation in China. The DEA model is used to measure the ecological efficiency of 30 regions in China by using the data from 2007 to 2017, and different spatial econometric models were used to explore the influencing factors of ecological efficiency. The results show that in terms of ecological efficiency, the western region has the highest ecological efficiency, and the eastern region has the lowest. However, with the acceleration of urbanization, the ecological efficiency of the three regions gradually declined, and the last three regions basically remained at the same level. Based on spatial econometric analysis, the relationship between technological innovation and ecological efficiency is discussed. The results show that technological innovation has a negative impact on ecological efficiency, which confirms the existence of the environmental Kuznets Curve. In addition, environmental regulation and education level can improve ecological efficiency, while urbanization rate can reduce ecological efficiency. At the same time, spatial spillover effect plays an important role in technological innovation, environmental regulation, education level and urbanization rate in the change of regional ecological efficiency. Policy recommendations for further strengthening environmental protection and sustainable development are discussed.

Key words: Technological innovation; Ecological efficiency; Spatial econometric models; China.

\section{Introduction}

After the reform and opening-up in the last century, China has made great progress in 
economy and has become one of the most important economies in the world. However, the take-off of China's economy is mainly driven by the extensive development mode. The rise of Chinese industrial civilization has brought prosperity, and at the same time, China has become the most serious environmental pollution country in the world. China is currently the largest fossil energy consumer in the world (Cui et al., 2019), and the most polluted country in the world (Yang et al., 2021); Lelieveld et al., 2015). At the same time, other environmental pollution problems such as soil pollution and air pollution have also appeared (Xue et al., 2019; Zhang et al., 2018; Bai et al., 2018; Feng et al 2021). In fact, the problem of ecological environment pollution has become a common concern topic all over the world, and all the world have made corresponding efforts to protect the environment. For example, South Korea took the lead in enacting the basic law on green growth (John and Mathew., 2012). Germany has always focused on the development of "ecological modernization" (jnicke., 2012). In 2012, the Chinese government proposed to integrate ecological civilization construction into the national strategy and formulated relevant laws and regulations. For example, the forest law of the people's Republic of China, the law of the people's Republic of China on the prevention and control of water pollution, and the law of the people's Republic of China on the prevention and control of air pollution, etc. Meanwhile, the Chinese government has committed to achieving peak carbon emissions by 2030 and establishing a national carbon trading market in 2017. Whether from the national strategic level or from the actual situation, attention to environmental issues, accelerating the construction of ecological civilization and improving ecological benefits have attracted the attention of scholars from all walks of life. Technological innovation is often used to explore the relationship between economic growth and the ecological efficiency. With the increasing of resource consumption and environmental problems, the research on ecological efficiency has gradually become the focus of attention, namely, the relationship between economic growth, eco-efficiency and technological innovation (Liu et al., 2020). However, there is little research on the relationship between 
technological innovation and ecological efficiency. The existing research on technology innovation and ecological efficiency is mostly about the relationship between urban technological innovation and ecological efficiency. Therefore, in order to make up for the literature blank in this field, this paper constructs the comprehensive evaluation index system of ecological efficiency and technological innovation from the perspective of technological innovation and ecological efficiency. DEA model and spatial econometric model were used to study the correlation effect and spatial effect of technological innovation and ecological efficiency in different provinces of China. Figure 1 is the theoretical framework of this paper.

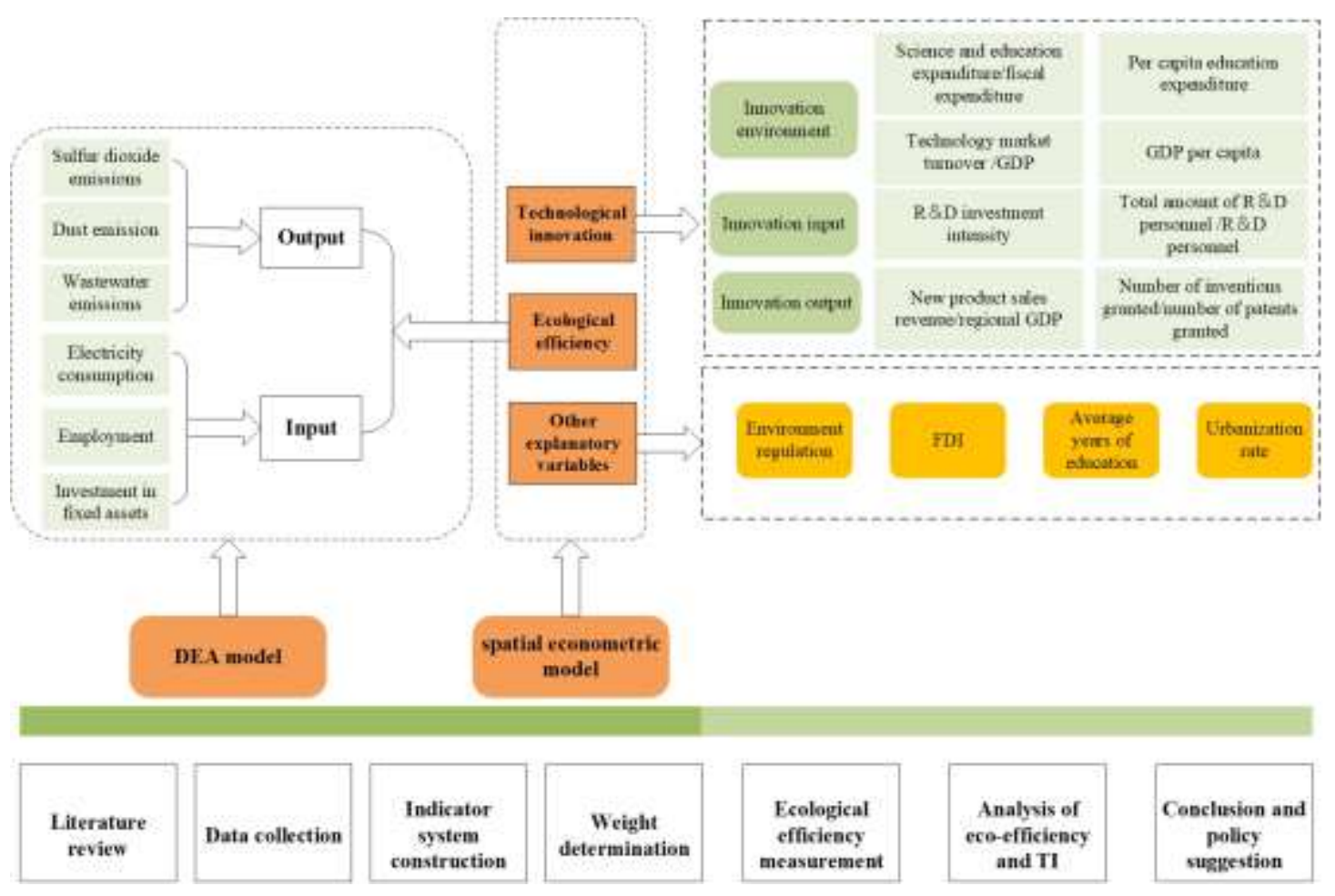

Fig 1. Theoretical framework of this paper

\section{Literature review}

\subsection{Ecological efficiency estimations}

Theoretically, ecological efficiency is an important index to measure ecological construction. It was first proposed by Sturm and Schaltegger (1990), who defined the goal of eco-efficiency as the unification of economic value and environmental benefit. Ecological efficiency can effectively measure the relationship between economic resources and environment, which is vital to evaluate the unified development of 
103 socioeconomic (Govindan et al., 2019; Liu et al., 2020; Wang et al., 2019; Caiado et 104 al., 2017). At present, scholars' research on ecological efficiency mainly focuses on two 105 aspects, the first is about the measurement of ecological efficiency. Some scholars 106 studied the ecological efficiency of regional tourism based on the perspective of China's 107 regional tourism, it is found that the tourism industry and ecology efficiency exist 108 obvious spatial spillover, although it is often considered to be environmentally friendly 109 tourism industry, but in recent years, the rapid growth of tourism has failed to 110 compensate for the destruction of the ecological environment, even if it is the common 111 problem (Sun et al., 2021; Chen et al., 2020). Scholars found that China has achieved a 112 win-win situation of environmental protection and economic growth during the 113 industrial transformation and upgrading in recent years by including industrial 114 wastewater and exhaust emissions in the assessment of ecological efficiency (Shao et 115 al., 2019; Chen et al., 2020). Some scholars also evaluated the provincial ecological 116 efficiency by studying the two subsystems of household pollution control and industrial 117 pollution control, and found that the ecological efficiency of economically developed 118 areas was better than that of economically underdeveloped areas (Zhang et al., 2020). 119 More scholars have studied China's eco-efficiency from a regional perspective (Xue et 120 al., 2021; Ren et al., 2019; Yang et al., 2021). The empirical results show that, in terms 121 of urban eco-efficiency, the regional eco-efficiency in China generally presents a 122 gradually decreasing situation from the east to the west. In terms of the time span, the 123 regional eco-efficiency mainly presents a U-shape.

124 The second is to explore the factors of ecological efficiency. FDI has a significant 125 impact on ecological efficiency, FDI has a significant impact on ecological efficiency. 126 Specifically, FDI will affect the ecological environment by transferring pollution 127 intensive enterprises to developing countries (Nasir et al., 2019; Pao, H. T., Tsai, C. M., 128 2011). The impacts of FDI on ecological efficiency are mainly pollution halo effect and 129 pollution sanctuaries. There are discussions about the pollution shelter and pollution 130 halo effect of FDI on regional ecological efficiency (Ren et al.,2020; Tong et al., 2020; 
131 Jun et al., 2018). China's natural gas, electricity and other energy supply industries have

132 higher ecological efficiency than mining and other industries, The main reason for the

133 high eco-efficiency is that China's oil and gas exploration and production areas are

134 under state control (Shao et al., 2019). Scholars also found that the upgrading of

135 industrial structure and educational level generally have a positive impact on ecological

136 efficiency (Han et al., 2021; Huang et al., 2020; Wang et al., 2020; Yasmeen et al., 2020).

$137 \quad 2.2$ Technological innovation and ecological efficiency

138 The theory of technological innovation has a long history and has been widely applied

139 (Guo et al., 2021; Vural., 2021; Wang et al., 2020). In 1934, Schumpeter (1934) applied

140 the theory of technological innovation to economic analysis. He proposed that

141 economic growth is an evolutionary process with innovation as the core. Many scholars

142 also studied the relationship between technological innovation and economic growth

143 (Liu and Zhang et al., 2021; Zhou et al.,2021). However, with the aggravation of 144 resource consumption and environmental pollution, people gradually turn their research

145 focus to the study of ecological efficiency, that is, the relationship between economic 146 growth, ecological efficiency and technological innovation (Liu et al., 2020; Deng and

147 Gibson., 2019). At present, most of the literature research is based on the perspective 148 of space to study the relationship between technological innovation and ecological 149 efficiency (Ali et al., 2021; Li et al., 2021). On the relationship between technological 150 innovation and ecological efficiency, scholars' research results are inconsistent. Some 151 scholars believe that technological innovation has a significant negative impact on 152 ecological efficiency, but the interaction between technological innovation and 153 industrial structure can improve regional ecological efficiency (Huang et al., 2020).

154 There are different relationships between technological innovation and ecological 155 efficiency. In the early stage of development, large-scale technological innovation will 156 have a siphon effect on the surrounding areas, while in the middle and late stage of 157 development, technological innovation will have a positive impact on the ecological 158 efficiency of surrounding cities through diffusion effect (Zhang et al., 2018; Hong and 

79

Zhang., 2016). Some scholars have studied the relationship between the two from the national level and found that the impact of technological innovation on the realization of sustainable development is different in countries at different development stages. For middle-income and high-income countries, technological innovation can bring sustainable progress. However, for low-income countries, there is no causal relationship between technological innovation and sustainable development (Ormi, 2020; Ormi, 2018; Surender and Shunsuke, 2010).

\section{Research methods}

\subsection{DEA model}

This paper uses DEA model to measure the ecological efficiency of 30 regions in China. Because of its objectivity, DEA is regarded as one of the effective methods to evaluate efficiency. Generally, DEA models are divided into CCR model with fixed scale return and BBC model with variable scale return. Combining CCR model with BCC model, ecological efficiency, pure technical efficiency and scale efficiency of each input index and output index can be determined simultaneously. The specific formula is as follows:

Firstly, it is assumed that there are $n$ decision making units, $X_{j}$ represents the input vector of the $j$ th decision making unit, $Y_{j}$ represents the output vector of the $j$ th decision making unit, $\theta$ represents the efficiency value, and $\lambda$ represents the weight. The linear programming equation of the CCR model is as follows:

$$
\left\{\begin{array}{c}
\min \theta \geq 0, \\
\text { s.t. } \sum_{j=1}^{n} X_{j} \lambda_{j} \leq \theta X_{0}, \\
\sum_{j=1}^{n} X_{j} \lambda_{j} \geq Y_{0}, \\
\lambda_{j} \geq 0 .
\end{array}\right.
$$

Adding constraints to weighted $\lambda$, a BBC model with variable returns to scale can be established. Its linear programming equation is as follows: 


$$
\left\{\begin{array}{c}
\min \theta, \\
\text { s.t. } \sum_{j=1}^{n} X_{j} \lambda_{j} \leq \theta X_{0}, \\
\sum_{j=1}^{n} Y_{j} \lambda_{j} \geq Y_{0}, \\
\sum_{j=1}^{n} \lambda_{j}=1, \\
\lambda_{j} \geq 0 .
\end{array}\right.
$$

183 Among them, $\theta$ represents the efficiency value of the ith DMU, it's $0 \leq \theta \leq 1$. When

$184 \theta<1$, The decision unit is represented as an invalid DEA.

\section{$185 \quad 3.2$ Space panel model}

186 Most of the studies on spatial spillover and correlation effects use spatial econometric models to measure. Generally, spatial econometric models mainly include Spatial Dobbin model (SDM), spatial autoregressive model (SAR) and spatial error model (SEM). Among them, Spatial Dobbin model appears in scholars' literature as a more general model. The spatial autoregressive model and the spatial five error model are all evolved from the Spatial Dobbin model. Then, the SDM model can be presented as

192 follows:

$$
e f f_{i t}=\rho W e f f_{i t}+x_{i t} \beta+W X_{i t} \delta+k_{i}+v_{t}+\mu_{i t}
$$

In the formula, eff ${ }_{i t}$ is explanatory variable, which means regional eco-efficiency in

China; $W$ is space weight matrix, in this paper, we would use $0-1$ matrix as the space weight matrix. Weff it is the spatial lag term of ecological efficiency, $\rho$ is spatial autoregressive coefficient. $x$ is the set of core explanatory variables, urban innovation behavior and other explanatory variables; $W X$ is the spatial lag term of explanatory variable and control variable, $\delta$ is the corresponding coefficient of each explanatory 200 variable; $k_{i} 、 v_{t}$ represent individual and time fixed effects. $\mu$ represent random 201 disturbance term. When $\delta=0$, the SDM model would degenerates into SAR model. 202 When $\delta+\rho \beta=0$, SDM model degenerates into SEM model.

203 In this paper, the $0-1$ adjacency matrix is chosen as the spatial weight matrix of the 204 spatial econometric model. the matrix is set as follows: 


$$
W_{i j}=\left\{\begin{array}{l}
1 \\
0
\end{array}\right.
$$

206 when region $i$ is adjacent to $j, W_{i j}=1$; when region $i$ is not adjacent to $j, W_{i j}=0$.

\section{4. Results and findings}

\section{$208 \quad 4.1$ Indicator selection and data source}

209 4.1.1 Regional ecological efficiency

210 In this paper, we choose DEA model to measure regional eco-efficiency of China.

211 Firstly, $\mathrm{SO}_{2}$ 、 industrial dust emissions and wastewater emissions are selected as output 212 indicators. Because city pollution discharge is the main source of city pollution.

213 Secondly, choose labor、 capital and resource as input indicators. Among them, choose 214 regional employment at the end of the year as the labor indicator, total fixed asset 215 investment by the end of the year as the capital indicator, as for resource indicators, 216 choose annual social electricity consumption because of data availability. All the data 217 come from China Statistical Yearbook, China City Statistical Yearbook and China 218 Science and Technology Statistical Yearbook (2008-2018). Considering the perennial 219 absence of data in Tibet, the measurement of Tibet will be excluded in this paper to 220 ensure the accuracy of data. And interpolation method is adopted to supplement 221 individual default values in other provinces. Detailed index selection is shown in Table 222 1:

Table 1. Input and output index system.

\begin{tabular}{ccc}
\hline System & Detailed indicators & Unit \\
\hline \multirow{2}{*}{ Output } & $\mathrm{SO}_{2}$ emissions & $\mathbf{1 0}^{4}$ tons \\
indicators & Dust emissions & $\mathbf{1 0}^{4}$ tons \\
& Wastewater emissions & $\mathbf{1 0}^{4}$ tons \\
Input & Electricity consumption & $\mathrm{KWH}$ \\
indicators & Employment & persons \\
& Investment in fixed assets & yuan \\
\hline
\end{tabular}

226 (1) Explained variable: The ecological efficiency previously measured by the DEA 
model is used as the explained variable, which is marked as eff.

\section{8 (2) explanatory variable:}

229 technological innovation: Technological innovation is calculated based on multi230 dimensional indicators. Based on the scientific, operability and data availability of the 231 indicators, this paper constructs a comprehensive index system of technological 232 innovation, which mainly includes three first-level indicators of innovation 233 environment, innovation input and innovation output and nine second-level indicators. 234 Specific indicators are shown in Table 2.

235 Environment regulation: There are plentiful literatures demonstrated that the impact of 236 environmental regulation on ecological efficiency (Cheng et al., 2019; Rubashkina et 237 al., 2015), most of them concluded through econometric models that environmental 238 regulation had a positive impact on eco-efficiency, and concluded that there was a U239 shaped relationship between environmental regulation, technological innovation and eco-efficiency, which verified the Porter Hypothesis (Porter 1991; Porter and van der

241 Linde 1995). In this paper, we defined environmental regulation as artificial 242 intervention to the environment. Therefore, the proportion of environmental protection 243 personnel in employment, the proportion of environmental expenditure in fiscal 244 expenditure and the harmless disposal rate of household garbage in each region were 245 selected as the indicators of environmental regulation, and a comprehensive index was 246 calculated by TOPSIS method.

247 Average education years: People's education level will improve people's attention to 248 regional ecology or environmental protection, so the average number of years of 249 education in the region was selected as one of the control variables.

250 FDI: FDI always considered to promote the economic growth of a region, and FDI has 251 proved to be an important engine for China's economic growth. From empirical 252 experience, it is generally believed that FDI will produce pollution sanctuary effect and 253 pollution halo effect on the ecological environment (Nancy et al 1993). Studies by some 254 scholars show that the impact of FDI on ecological efficiency is different in different 
stages of economic development, FDI has a negative impact on ecological efficiency

256 when the level of economic development is low. Only when the economic level exceeds

257 a group of thresholds, FDI can contribute to the improvement of ecological efficiency

258 (Tong et al, 2020). Therefore, we take the proportion of FDI in GDP as one of the

259 indicators

260 Industrial structure: It is generally believed that industrial structure has a great impact

261 on ecological efficiency. The ecological efficiency of regions with a large proportion of

262 primary and tertiary industries is usually better than that of regions with developed

263 secondary industries. In this paper, we use the location quotient of the output value of

264 the secondary industry in each region as the index of industrial structure.

265 Urbanization: China is a vast country. In the early stage, the urbanization level of

266 different regions in China varies greatly, but since the Reform and opening-up, all

267 regions in China have accelerated the urbanization process. Generally, urbanization has

268 a negative impact on regional ecological efficiency in China (Tang et al 2020; Yasmeen

269 and Humaira., 2020). Therefore, the urbanization level of each region in China is

270 selected as one of the indicators in this paper.

Table 2. Technological Innovation index system.

\begin{tabular}{ccc}
\hline Level indicators & The secondary indicators & Unit \\
\hline & Science and education expenditure/fiscal & $\%$ \\
Innovation environment & expenditure & $\%$ \\
& Technology market turnover /GDP & RMB \\
& Per capita education expenditure & RMB \\
Innovation input & GDP per capita & $\%$ \\
& Total amount of R\&D personnel /R\&D personnel & $\%$ \\
Innovation output & New product sales revenue/regional GDP & $\%$ \\
& Number of inventions granted/number of patents & $\%$ \\
\hline
\end{tabular}

\section{$273 \quad 4.2$ Measurement of regional ecological efficiency in Chinese provinces}

274 We have analyzed China's regional ecological efficiency in two aspects. First, we have

275 estimated the ecological efficiency of 30 provinces in China. Second, China is divided

276 into East, central and West according to China's administrative divisions. The regional 
ecological efficiency is measured by subregions. The ecological efficiency of these three regions is obtained by averaging the ecological efficiency scores of each division, The results of regional ecological efficiency are shown in Table 3 and Figure 2. From 2007 to 2010, during China's Tenth Five Year Plan period, China's overall regional ecological efficiency showed a slight downward trend. In this time, the overall ecological efficiency was not high. After 2011, China's ecological efficiency gradually increased, taking 2013 as the inflection point, and then the rising speed gradually accelerated. In 2015, the ecological efficiency of various regions in China peaked. From the divided regions, there is a large gap in ecological efficiency among the three regions in China, showing a trend of the lowest in the East, the second in the middle and the highest in the West. The change trend of ecological efficiency in the three regions is relatively gentle. From the perspective of provinces, Guizhou and Ningxia Hui autonomous regions have the highest ecological efficiency, while Fujian and Zhejiang have the lowest ecological efficiency. Fujian and Zhejiang are the most

291 developed coastal areas in China. They have a high level of urbanization, developed 292 industry and commerce, and many highly polluting enterprises, which is in line with 293 the actual situation.

294 However, after the inflection point in 2013, the ecological efficiency of eastern and 295 central China began to show an accelerated upward trend, and the Western China 296 showed a slow upward trend. The gap between the ecological efficiency values of the three regions began to narrow gradually. In 2014, the ecological efficiency gap between

298 the three regions has narrowed to 0.039. By 2015, the ecological efficiency of the 299 central region surpassed that of Western China for the first time, reaching the highest 300 value of 0.96925 in 11 years. Since then, the ecological efficiency value of the central 301 region has been the highest, followed by the western region and the eastern region. 302 Compared with 2007, the gap between the three regions has been greatly narrowed. The 303 possible reason is that the eastern region developed earlier and the urbanization rate is higher. In the early stage of China, many highly polluting enterprises were concentrated, 
305 resulting in the discharge of many industrial polluting wastes and poor ecological

306 environment. On the contrary, the western region is still at a low level of urbanization

307 and development, with a good natural environment and high ecological efficiency. With

308 the implementation of policies such as the development of western China and the rise

309 of central China, the central and western regions began to undertake high-pollution

310 enterprises in the eastern regions, which led to the decline and continuous decline of

311 ecological efficiency in various regions in China in recent years. In 2013, the Chinese

312 government launched a nationwide environmental protection inspection campaign.

313 Lots of productive enterprises with high pollution were punished according to law,

314 resulting in a rapid increase in regional ecological efficiency.

Table 3. Regional ecological efficiency based on DEA.

\begin{tabular}{|c|c|c|c|c|c|c|c|c|c|c|c|c|}
\hline & Region & 2007 & 2008 & 2009 & 2010 & 2011 & 2012 & 2013 & 2014 & 2015 & 2016 & 2017 \\
\hline \multirow{11}{*}{$\begin{array}{c}\text { Easte } \\
\text { rn } \\
\text { Regio } \\
\text { n }\end{array}$} & Beijing & 0.357 & 0.364 & 0.37 & 0.39 & 0.423 & 0.39 & 0.341 & 1 & 0.884 & 0.929 & 0.805 \\
\hline & Tianjin & 0.489 & 0.398 & 0.398 & 0.356 & 0.399 & 0.412 & 0.457 & 0.895 & 0.597 & 0.618 & 0.671 \\
\hline & Hebei & 0.772 & 0.829 & 0.725 & 0.746 & 1 & 0.822 & 0.99 & 1 & 1 & 1 & 1 \\
\hline & Liaoning & 1 & 1 & 0.91 & 0.957 & 0.916 & 0.893 & 0.975 & 1 & 1 & 1 & 1 \\
\hline & Shanghai & 0.362 & 0.391 & 0.399 & 0.317 & 0.291 & 0.342 & 0.369 & 1 & 1 & 1 & 1 \\
\hline & Jiangsu & 0.368 & 0.362 & 0.358 & 0.37 & 0.361 & 0.359 & 0.341 & 0.691 & 0.783 & 0.823 & 0.78 \\
\hline & Zhejiang & 0.265 & 0.29 & 0.287 & 0.243 & 0.275 & 0.298 & 0.332 & 0.734 & 0.805 & 0.82 & 0.884 \\
\hline & Fujian & 0.28 & 0.292 & 0.318 & 0.28 & 0.277 & 0.283 & 0.334 & 0.495 & 0.763 & 0.717 & 0.71 \\
\hline & Shandong & 0.454 & 0.486 & 0.473 & 0.489 & 0.655 & 0.673 & 0.681 & 0.733 & 0.866 & 0.835 & 0.817 \\
\hline & $\begin{array}{c}\text { Guangdon } \\
\mathrm{g}\end{array}$ & 0.302 & 0.337 & 0.359 & 0.31 & 0.263 & 0.304 & 0.333 & 1 & 1 & 1 & 1 \\
\hline & Hainan & 0.493 & 0.418 & 0.384 & 0.319 & 0.403 & 0.343 & 0.338 & 0.816 & 0.749 & 0.855 & 0.869 \\
\hline \multirow{8}{*}{$\begin{array}{c}\text { Cent } \\
\text { ral } \\
\text { regio } \\
\text { n }\end{array}$} & Shanxi & 1 & 1 & 0.943 & 0.88 & 1 & 1 & 1 & 1 & 1 & 1 & 1 \\
\hline & Jilin & 1 & 1 & 1 & 0.965 & 0.908 & 0.692 & 0.772 & 0.922 & 1 & 0.844 & 1 \\
\hline & $\begin{array}{l}\text { Heilongjia } \\
\text { ng }\end{array}$ & 1 & 1 & 0.973 & 1 & 1 & 1 & 1 & 1 & 1 & 1 & 1 \\
\hline & Anhui & 0.564 & 0.544 & 0.482 & 0.471 & 0.485 & 0.433 & 0.464 & 0.823 & 1 & 0.896 & 0.874 \\
\hline & Jiangxi & 0.71 & 0.676 & 0.712 & 0.685 & 0.912 & 0.986 & 0.889 & 0.916 & 1 & 1 & 1 \\
\hline & Henan & 0.673 & 0.658 & 0.625 & 0.641 & 0.605 & 0.604 & 0.665 & 0.713 & 0.861 & 0.736 & 0.736 \\
\hline & Hubei & 0.369 & 0.347 & 0.338 & 0.34 & 0.374 & 0.378 & 0.435 & 0.845 & 0.893 & 0.785 & 0.781 \\
\hline & Hunan & 0.854 & 0.715 & 0.644 & 0.623 & 0.556 & 0.574 & 0.676 & 0.903 & 1 & 1 & 1 \\
\hline \multirow{5}{*}{$\begin{array}{l}\text { West } \\
\text { regio } \\
\text { n }\end{array}$} & Guangxi & 1 & 0.884 & 0.822 & 0.89 & 0.571 & 0.564 & 0.604 & 0.785 & 1 & 0.946 & 0.96 \\
\hline & Chongqing & 1 & 1 & 1 & 1 & 1 & 1 & 1 & 1 & 0.979 & 1 & 1 \\
\hline & Sichuan & 0.675 & 0.615 & 0.578 & 0.638 & 0.524 & 0.545 & 0.473 & 0.689 & 0.909 & 0.916 & 0.926 \\
\hline & Guizhou & 1 & 1 & 1 & 1 & 1 & 1 & 1 & 1 & 1 & 1 & 1 \\
\hline & Yunnan & 0.51 & 0.463 & 0.432 & 0.42 & 0.577 & 0.602 & 0.559 & 0.686 & 0.909 & 1 & 0.907 \\
\hline
\end{tabular}




$\begin{array}{cccccccccccc}\text { Shaanxi } & 0.813 & 0.776 & 0.716 & 0.69 & 0.857 & 0.809 & 0.865 & 0.846 & 0.95 & 0.751 & 0.737 \\ \text { Gansu } & 0.711 & 0.695 & 0.761 & 0.83 & 0.802 & 0.798 & 0.81 & 0.869 & 0.806 & 0.668 & 0.617 \\ \text { Qinghai } & 0.797 & 0.995 & 1 & 0.815 & 1 & 1 & 1 & 1 & 1 & 0.921 & 0.95 \\ \text { Ningxia } & 1 & 1 & 1 & 1 & 1 & 1 & 1 & 1 & 1 & 1 & 1 \\ \text { Xinjiang } & 1 & 1 & 1 & 1 & 1 & 1 & 1 & 0.918 & 0.815 & 0.754 & 0.87 \\ \text { Inner } & 1 & 1 & 1 & 1 & 0.966 & 1 & 0.994 & 1 & 1 & 0.87 & 0.897 \\ \text { Mongolia } & & & & & & & & & & & \end{array}$

316

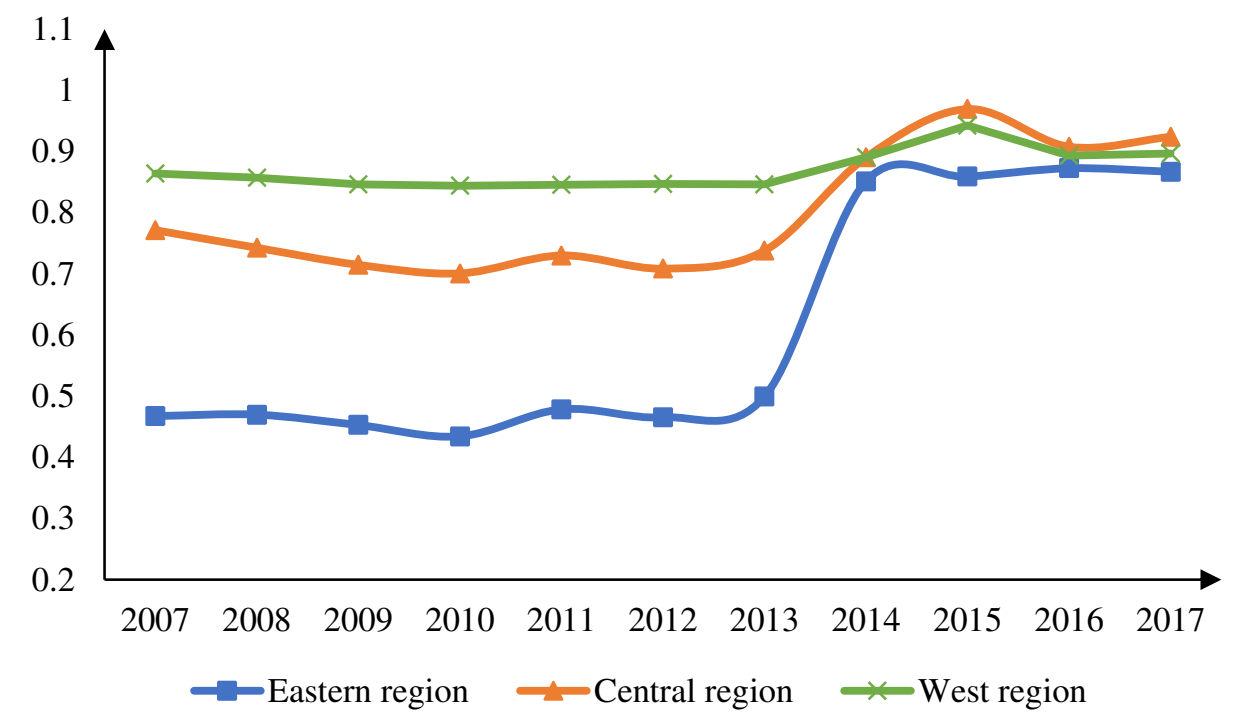

Fig 2. Eco-efficiency trends in different regions of China

\section{$319 \quad 4.3$ Spatial econometric model}

320 In combination with the availability and operability of the data, ecological efficiency

321 was taken as the explanatory variable, and technological innovation, environmental

322 regulation, industrial structure, and urbanization rate were taken as the core

323 explanatory variables. Descriptive statistical results are shown in the following table

324 4:

Table 4. Descriptive statistics of specific variables

\begin{tabular}{lccccc}
\hline Variables & $\mathrm{N}$ & mean & sd & $\min$ & $\max$ \\
\hline Number & 330 & 15.500 & 8.669 & 1.000 & 30.000 \\
Year & 330 & 2012 & 3.167 & 2007 & 2017 \\
Effi & 330 & 0.756 & 0.250 & 0.243 & 1.000 \\
TI & 330 & 0.292 & 0.168 & 0.043 & 0.847 \\
ENR & 330 & 0.354 & 0.232 & 0.001 & 1.001 \\
Edu & 330 & 0.341 & 0.207 & 0.000 & 1.001 \\
FDI & 330 & 0.053 & 0.056 & 0.000 & 0.268 \\
INC & 330 & 0.940 & 0.678 & 0.062 & 3.226
\end{tabular}




\begin{tabular}{llllll} 
UR & 330 & 0.336 & 0.248 & 0.001 & 1.001 \\
\hline
\end{tabular}

327 As suggested by Anselin (1998), the maximum likelihood method (MLE) is used to 328 estimate the spatial panel model. Before the estimation of the model, the spatial 329 correlation of variables and the selection of the model should be tested. Moran'I test 330 was carried out on the average value of the data from 2007 to 2017 , and the result 331 showed that the value of Moran index was 0.388 under the $0-1$ weight matrix, and the 332 condition was significant under another $1 \%$. Therefore, it is necessary to construct 333 spatial econometric model. The null hypothesis is rejected when the LR test statistics 334 are all $1 \%$, which indicates that the more generalized SDM model is the best form to 335 use the spatial panel. In order to show the results more accurately, the results of SDM, 336 SAR and SEM models are presented, and the results of SAR and SEM are used for 337 comparative analysis.

338 The results obtained through calculation are shown in Table 5:

Table 5. Spatial panel basic regression results.

\begin{tabular}{cccc}
\hline & SDM & SAR & SEM \\
\hline LnTI & $-0.191^{* * *}$ & $-0.315^{* * *}$ & $-0.320^{* * *}$ \\
\hline LnEnr & {$[0.050]$} & {$[0.047]$} & {$[0.044]$} \\
& $0.108^{* * *}$ & $0.088^{* * *}$ & $0.097 * * *$ \\
LnEdu & {$[0.017]$} & {$[0.016]$} & {$[0.017]$} \\
& $0.044^{* * *}$ & $0.035^{* *}$ & $0.028^{* *}$ \\
LnINC & {$[0.013]$} & {$[0.0111]$} & {$[0.011]$} \\
& -0.043 & -0.052 & -0.051 \\
LnFDI & {$[0.026]$} & {$[0.029]$} & {$[0.031]$} \\
& -0.011 & -0.027 & $-0.040^{*}$ \\
LnUR & {$[0.0285]$} & {$[0.027]$} & {$[0.0306]$} \\
& $-0.0424 *$ & 0.004 & 0.002 \\
& {$[0.019]$} & {$[0.017]$} & {$[0.016]$} \\
& $0.276^{*}$ & & \\
& {$[0.121]$} & &
\end{tabular}




$$
\begin{aligned}
& \text { w. LnEnr } \quad 0.132 * * * \\
& \text { [0.038] } \\
& \text { w.LnEdu } \quad 0.079 * \\
& \text { [0.031] } \\
& \text { w. } \operatorname{Ln} L N C \quad 0.038 \\
& \text { [0.047] } \\
& \text { w.LnFDI } \quad 0.034 \\
& \text { [0.035] } \\
& \text { w. LnUR } \quad-0.108^{*} \\
& \text { [0.047] } \\
& \begin{array}{llll}
\rho / \lambda & 0.395^{* * *} & 0.491^{* *} & 0.513^{* * * *}
\end{array} \\
& {[0.057] \quad[0.052] \quad[0.056]}
\end{aligned}
$$

340 Note: $* * *, * * *$ are significant under the conditions of $1 \%, 5 \%$, and $10 \%$, respectively. The data in

341 parentheses are P values. Source: Author's estimations.

342 As we can be seen from Table 5, among all influencing factors, environmental 343 regulation has the greatest positive impact on ecological efficiency, with a ratio of 0.108 .

344 Technological innovation was the lowest, with a ratio of -0.191 . This means that for 345 each increase of technological innovation, the ecological efficiency will decrease by 346 0.191. Technological innovation has no positive effect on regional ecological efficiency. 347 The possible reason is that with the increasing pressure of environmental protection in 348 recent years, the intensity of regional innovation research and development has been 349 restrained. From the perspective of space spillover, technological innovation has a 350 positive impact on the ecological environment. The possible reason is that with the 351 increase of inter-regional environmental protection pressure, highly polluting and 352 efficient enterprises may be moved to the surrounding areas, which will not only bear 353 the high pollution of enterprises, but also benefit from enterprises. The surrounding 354 areas can invest economic benefits into R\&D innovation, which will lead to the positive 355 impact of surrounding technological innovation on ecological efficiency. 
356 The positive correlation effect of environmental regulation on regional ecological 357 efficiency is the largest, and the specific value is 0.108 , which passes the $1 \%$ test. The 358 results show that environmental regulation plays a good role in improving regional 359 ecological efficiency. At the same time, the spatial lag term of environmental regulation 360 is also significantly positive, indicating that environmental regulation not only has a 361 good impact on the ecological efficiency of the region, but also has a good impact on 362 the green development of other regions through spillover effect. The average number 363 of years of education also has a positive impact on regional ecological efficiency, with 364 a specific value of 0.0442 , passing the $1 \%$ test. Its spatial lag term also passed the $1 \%$ 365 test, with a specific value of 0.132 , indicating that the increase of people's years of 366 education will improve people's environmental awareness, and the improvement of 367 people's overall environmental awareness will also improve the surrounding ecological 368 efficiency through the spatial spillover effect. Both the coefficient of industrial structure 369 and the coefficient of opening to the outside world are negative, but not significant. The 370 urbanization rate is negatively correlated with the regional ecological efficiency, and 371 the spatial spillover term coefficient is also negative, both of which pass the $10 \%$ test, 372 and the small coefficients are -0.0424 and -0.108 , respectively. This indicates that the 373 urbanization rate will have a negative impact on the regional ecological efficiency, 374 which is also consistent with the actual situation. In recent years, China has been 375 advancing its urbanization process, with the urbanization rate exceeding 50 percent in 376 2012. The rapid urbanization process will cause damage to the ecological environment, 377 thus reducing the ecological efficiency.

378 By analyzing the spatial effect of empty panels, the specific results are shown in Table 3796 :

Table 6. Results of spatial spillover effect

\begin{tabular}{lccc}
\hline \multirow{2}{*}{ Variables } & Coef & Direct & Indirect \\
\hline \multirow{2}{*}{ LnTI } & $-0.191^{* *}$ & $-0.167^{* *}$ & 0.306 \\
LnEnr & $(-3.8)$ & $(-2.84)$ & $(-0.098)$ \\
& $0.108^{* * *}$ & $0.127^{* * *}$ & $0.275^{* * *}$
\end{tabular}




$\begin{array}{cccc} & (-6.39) & (-7.44) & (-5.03) \\ \text { LnEdu } & 0.442 * * * & -0.057 * & 0.153 * * \\ & (-3.54) & (-4.01) & (-2.99) \\ \text { LnINC } & -0.011 & -0.008 & 0.043 \\ & (-0.60) & (-0.41) & (-0.79) \\ \text { LnFDI } & -0.043 * & -0.399 & 0.036 \\ & (-1.52) & (-1.46) & (-0.625) \\ \text { LnUR } & -0.042 * * * & -0.057 * * & -0.199 * \\ & (-4.87) & (-2.61) & (-2.48)\end{array}$

381 According to the analysis results, the direct effect of technological innovation on ecological efficiency is negative and has passed the $1 \%$ test, but the indirect effect is

383 not obvious. The possible reason is that China has gradually strengthened the awareness 384 of ecological environment protection in recent years. The punishment for the 385 enterprises with high pollution affecting the ecological environment is increased, which restrains the research and development of technological innovation, leading to the 387 negative impact of technological innovation on the ecological efficiency of the region. 388 Environmental regulation has a significant positive impact on the ecological efficiency, 389 which not only has a good impact on the regional ecological efficiency but also has a 390 spillover effect on the surrounding areas. The average length of education of residents 391 has a good effect on the ecological efficiency, the direct effect is negative, but the more 392 obvious is a positive indirect effect. The possible reason is that with the increasingly 393 perfect regional transportation system in China, there are more exchanges between 394 different regions, and the increase of residents' years of education has produced a 395 greater spatial spillover effect. The direct and indirect effects of FDI and industrial structure are not significant. The direct and indirect effects of urbanization rate have 397 passed the test of $5 \%$ and $10 \%$ respectively, and the coefficient is negative. It shows 398 that urbanization has a negative effect on regional ecological efficiency, which is 399 consistent with the actual situation. Although China's urbanization has promoted 400 economic development and the optimization and upgrading of industrial structure, it 401 has also brought a series of ecological and environmental problems, such as urban heat 402 island effect, haze effect, congestion effect and garbage effect. 
404 An interesting finding is that, at the beginning of the study in 2007, China's regional 405 ecological efficiency was not high and even showed a downward trend, which was 406 inseparable from the extensive economic development mode of that year (Wang and 407 Feng., 2020). During the period of the tenth Five-year Plan (2006-2010), When China's 408 social economy was in the stage of rapid development, there was no clear limit on the 409 emission of environmental pollutants, and the economic development in this period was 410 at the cost of environmental pollution (Wang and Feng., 2021). Since 2011, China has 411 entered the 12th Five-Year Plan period. During this period, Chinese leaders put forward 412 a long-term plan for the country's overall industrial transformation and upgrading from 413 extensive development to intensive development under the impetus of domestic and 414 foreign factors (Liu et al., 2020). Since 2012, China's regional ecological efficiency has 415 been gradually increasing. This is because the 18th National Congress of the 416 Communist Party of China in that year identified ecological civilization construction 417 and the realization of sustainable development as an important national strategy. At the 418 same time, the eastern region, China's economic center of gravity, has accelerated 419 industrial transformation and upgrading, the relocation of highly polluting enterprises 420 and environmental pollution control. In 2015, the Chinese government established the 421 Central Environmental Inspection Team (Tan and Mao., 2020). The main purpose is to 422 monitor the strict implementation of pollution control measures by enterprises. 423 Therefore, since 2015, the eco-efficiency of all regions has maintained a high level, 424 forming a peak in this period.

425 Another interesting finding is that although technological innovation has a negative 426 impact on the improvement of ecological efficiency, environmental regulation has a 427 significant positive impact on the improvement of ecological efficiency, which is also 428 consistent with the views of some scholars (Guo et al., 2017). They believe that 429 environmental regulation can promote technological innovation and thus promote 430 regional green growth performance. At the same time, the development of urbanization 431 will have a negative impact on ecological efficiency, which is consistent with the 
432 Proposal of "Paris Agreement" to control the scale of urbanization as one of the 433 measures to protect the ecological environment (Yasmeen and Humaira). This is 434 because the development of urbanization means changes in land use, population living, 435 production and lifestyle. FDI has a negative impact on ecological efficiency because 436 China's economy has been at a low level for a long time. Foreign direct investment is 437 more about introducing pollution intensive enterprises into China. The rapid and lowquality development leads to the "pollution paradise hypothesis" (Tong et al., 2020;

439 Nasir et al., 2019; Shahbaz et al., 2015).

\section{Conclusion and policy suggestions}

441 In this article, we constructed a scientific regional ecological efficiency evaluation 442 model including output indicators and input indicators, and calculates the regional 443 ecological efficiency of various provinces and regions in China by DEA model. Then, 444 the relationship between ecological efficiency and technological innovation and other control variables is analyzed by spatial econometric model. The empirical results show that the regional ecological efficiency is Gradually decrease from Western China to Eastern China. With the development of China's industrialization, the highly polluting industries in the developed eastern regions are gradually transforming to those in the central and western regions, resulting in the improvement of ecological efficiency in the eastern region year by year. The ecological efficiency of the central and western regions has gradually decreased, and the gap between the three has gradually narrowed. In the second stage, the spatial econometric model is used to analyze the main factors affecting regional ecological efficiency in China. The results show that there is a significant spatial spillover effect in China's regional ecological efficiency. Innovation has a significant negative impact on ecological efficiency. With the pressure of environmental protection in various regions, technological innovation has a positive

457 impact on the ecological efficiency of surrounding areas. Environmental regulation is 458 the most effective means to improve ecological efficiency. In addition, the main factors affecting ecological efficiency are the length of education of local residents and the 
efficiency of urbanization. These influencing factors will have a certain spatial spillover effect, which will not only affect the region, but also have a spillover effect on the surrounding areas.

The above conclusions have the following suggestions and Enlightenment: first, we still pay attention to the management of technological innovation and the direction of guiding technological innovation in the ecological environment. Not only in terms of input, but also in terms of output, we need to pay attention to promote the application of technological innovation in ecological environment governance. Give policy support from the three dimensions of innovation environment construction, innovation output and innovation investment. We will strengthen the protection of invention patents, simplify administrative examination and approval procedures, and accelerate the popularization and application of patent achievements. In order to give full play to the leading role of technological innovation in regional ecological environment protection and promote national green development. Second, speed up the development process of technological innovation, better match the governance of regional ecological efficiency, create good conditions for the spillover effect of technological innovation, expand the scope of spillover effect, comply with China's current urban agglomeration development strategy, and accelerate out of the "U-shaped line" transition zone. Third, pay attention to the coordination between technological innovation and other regulatory factors, and create a good technological innovation environment. For regions with relatively developed and balanced economic development in eastern and southeastern China, we should pay attention to accelerating the research and development of green intelligent manufacturing technology, modern energy technology and the application of key technologies. For regions with unbalanced economic development in Western China, such as external spillovers, we should accelerate the innovation space to improve the overall innovation ability of the region, promote coordinated regional and urban economic development and green transformation. Fourth, in terms of the impact of other control variables, we should reasonably control China's urbanization process; For 
488 foreign direct investment, we need to strengthen supervision, improve the quality of 489 foreign investment introduction, and promote the realization of China's sustainable 490 development.

492 Authors' Contributions Huan Huang: Conceptualization, Investigation; Jiaxin Kuang: 493 Methodology, Writing-review \& editing, Roles/Writing-original dra; Fan Wang: Formal 494 analysis, Validation; Ke Tian: Visualization, Software; Supervision; Yi Xiao: Data 495 curation, Project administration, Resources.

496 Funding This work was supported by the National Natural Science Foundation of 497 China (41790445, 42042019); National Social Science Foundation of China 498 (19FJYB028); Social Science Planning Major Project of Sichuan Province 499 (SC20ZDCY001); Social Science Key Research Base of Sichuan Province 500 (xy2020074); Independent Project Foundation of State Key Laboratory 501 (SKLGP2015Z004).

502 Data availability The datasets used during the current study are available from the 503 corresponding author on reasonable request.

\section{Compliance with ethical standards}

505 Conflict of interest The author declare that they have no competing interests.

506 Ethical approval Not applicable.

507 Consent to participate Not applicable.

508 Consent to publish Not applicable.

\section{$510 \quad$ Reference}

511 Ali, S. A., Alharthi, M., Hussain, H. I., Rasul, F., Hanif, I., Haider, J., Ullah, S., 512 Rahman, S. U., Abbas, Q., 2021. A clean technological innovation and eco-efficiency 513 enhancement: A multi-index assessment of sustainable economic and environmental 
management. Technological Forecasting and Social Change 166, 120573.

Bai, Y. P., Deng, X. Z., Jiang, S. J., Zhang, Q., Wang, Z., 2018. Exploring the relationship between urbanization and urban eco-efficiency: Evidence from prefecturelevel cities in China. Journal of Clean Production 195, 1487-1496.

Caiado, G. G. R., Dias, R. D. F., Mattos, L. V., Quelhas, O. L. G., Filho, W. L., 2017. Towards sustainable development through the perspective of eco-efficiency - a systematic literature review. Journal of Cleaner Production, 165nov.1, 890-904.

Chen, H. B., Dong, K., Wang, F. F., Ayamba, E. C., 2020. The spatial effect of tourism economic development on regional ecological efficiency. Environmental Science and Pollution Research, 2710, 1-18.

Chen, X., Lin, B., 2020. Assessment of eco-efficiency change considering energy and environment: a study of China's non-ferrous metals industry. Journal of Cleaner Production, 277.

Cheng, Y. Y., Shao, T. Y., H Lai, H. L., Shen, M. H., Li, Y., 2019. Total-Factor EcoEfficiency and Its Influencing Factors in the Yangtze River Delta Urban Agglomeration, China. International Journal of Environmental Research and Public Health, 1620, 3814. Cui, D., Chen, X., Xue, Y. L., Li, R., Zeng, W. H., 2019. An integrated approach to investigate the relationship of coupling coordination between social economy and water environment on urban scale - a case study of Kunming. Journal of Environmental Management 234, 189-199.

Deng, X. Z., Gibson, J., 2019. Technological Forecasting and Social Change 144, 394-400.

Discussion:

Feng, Y. C., Wang, X. H., Liang, Z., 2021. How does environmental information disclosure affect economic development and haze pollution in Chinese cities? The mediating role of green technology innovation. Science of Total Environment 775, 145811.

Ghisetti, C., Quatraro, F., 2017. Green technologies and environmental 
productivity: a cross-sectoral analysis of direct and indirect effects in Italian regions. Ecological Economics 132, 1-13.

Govindan, K., Jha, P. C., Agarwal, V., Darbari, J. D., 2019. Environmental management partner selection for reverse supply chain collaboration: a sustainable approach. Journal of Environmental Management, 236APR.15, 784-797.

Guo, H., Yang, J., Han, J. P., 2021. The Fit Between Value Proposition Innovation and Technological Innovation in the Digital Environment: Implications for the Performance of Startups. IEEE Transactions on Engineering Management 68, 797-809.

Guo, L. L., Qu, Y., Tseng, M. L., 2017. The interaction effects of environmental regulation and technological innovation on regional green growth performance. Journal of Cleaner Production, 162sep.20, 894-902.

Han, Y. H., Zhang, F., Huang, L. X., Peng, K. M., 2021. Does industrial upgrading promote eco-efficiency? - a panel space estimation based on Chinese evidence. Energy Policy $154,112286$.

Hong, J. Y., Zhang, C. H., 2016. Research on the effectiveness of enterprise technological innovation to improve ecological efficiency. On Economic Problem 16 $12,71-76$.

Huang, M., Ding, R. J., Xin, C. H., 2020. Impact of technological innovation and Industrial-Structure Upgrades on Ecological Efficiency in China in Terms of Spatial Spillover and the threshold effect. Integrated Environmental Assessment and Management,

Huang, M., Ding, R. J., Xin, C. H., 2021. Impact of Technological Innovation and Industrial - structure Upgrades on Ecological Efficiency in China in Terms of Spatial Spillover and the Threshold Effect. Integrated environmental assessment and management,

Janicke, M., 2012. "Green growth": From a growing eco-industry to economic sustainability. Energy Policy 48, 13-21.

John, A., Mathew., 2012. Green growth strategies - Korean initiative. Futures 448, 
761-769.

Jun, W., Zakaria, M., Shahzad, S. J. H., Mahmood, H. 2018. Effect of FDI on pollution in China: new insights based on wavelet approach. Sustainability, 1011.

Lelieveld, J., Evans, J. S., Fnais, M., Giannadaki, D., Pozzer, A., 2015. The contribution of outdoor air pollution sources to premature mortality on a global scale. Nature 5257569, 367-371.

Li, X. F., Ma, D. L., 2021. Financial agglomeration, technological innovation, and green total factor energy efficiency. Alexandria Engineering Journal 60, 4085-4095.

Liu, Q. Q., Wang, S. J., Li, B., Zhang, W. Z., 2020. Dynamics, differences, influencing factors of eco-efficiency in China: a spatiotemporal perspective analysis. Journal of Environmental Management, 264, 110442.

Liu, X., Zhang, X., 2021. Industrial agglomeration, Technological Innovation and carbon productivity: evidence from China. Resources Conservation and Recycling. $1662,105330$.

Liu, Y. Q., Zhu, J. L., 2020. Environmental regulation, green technological innovation, and eco-efficiency: the case of Yangtze River economic belt in China. Technological Forecasting and Social Change 155, 119993.

Liu, Y. Q., Zhu, J. L., Li, E. Y., Meng, Z. Y., Song, Y., 2020. Environmental regulation, green technological innovation, and eco-efficiency: The case of Yangtze River economic belt in China. Technological Forecasting and Social Change, 155, 119993.

Nancy, B., David, W., 1993. Trade Policy and Industrial Pollution in Latin America: Where Are the Pollution Havens? The Journal of Environment \& Development, 21, 137-149.

Nasir, M. A., Huynh, T. L. D., Tram, H. T. X., 2019. Role of financial development, economic growth \& foreign direct investment in driving climate change: a case of emerging ASEAN. Journal of Environmental Management, 242JUL.15, 131-141.

Nasir, M. A., Huynh, T., Tram, H., 2019. Role of financial development, economic 
growth \& foreign direct investment in driving climate change: a case of emerging ASEAN. Journal of Environmental Management, 242JUL.15, 131-141.

Omri, A., 2018. Entrepreneurship, sectoral outputs and environmental improvement: international evidence. Technological Forecasting and Social Change $128,46-55$.

Omri, A., 2020. Technological innovation and sustainable development: Does the stage of development matter? Environmental Impact Assessment Review 83, 106398.

Pao, H., T., Tsai, C., M. 2011. Multivariate granger causality between co2 emissions, energy consumption, FDI foreign direct investment and GDP gross domestic product: evidence from a panel of BRIC Brazil, Russian Federation, India, and China countries. ENERGY -OXFORD-.

Ren, Y., Fang, C., Li, G., 2020. Spatiotemporal characteristics and influential factors of eco-efficiency in Chinese prefecture-level cities: a spatial panel econometric analysis. Journal of Cleaner Production, 260, 120787.

Ren, Y., Fang, C., Lin, X., Sun, S., Li, G., Fan, B., 2019. Evaluation of the ecoefficiency of four major urban agglomerations in coastal eastern China. J. Geogr, sci. 29, 1315-1330.

Rubashkina, Y., Galeotti, M., Verdolini, E., 2015. Environmental regulation and competitiveness: empirical evidence on the porter hypothesis from European manufacturing sectors. Energy Policy 83, 288-300.

Schaltegger, S., Sturm A., 1990. Ökologische Rationalität: Ansatzpunkte zur Ausgestaltung von ökologieorientierten Managementinstrumenten, Die Unternehmung 444, 273-290.

Schumpeter, J. A., Schumpeter, J., Schumpeter, J., Schumpeter, J. P., Schumpeter, J. A., Schumpeter, J., 1934. The theory of economics development. Journal of Political Economy, 12, 170-172.

Shahbaz, M., Nasreen, S., Abbas, F., Anis, O., 2015. Does foreign direct investment impede environmental quality in high-, middle-, and low-income countries? 
Energy Economics, 51, 275-287. industrial sectors: a two-stage network data envelopment analysis. Journal of

629 Environmental Management, 247, 551-560. industrial sectors: a two-stage network data envelopment analysis. Journal of Environmental Management, 247, 551-560.

Sun, Y. Y., Hou, G. L., 2021. Analysis on the Spatial-Temporal Evolution Characteristics and Spatial Network Structure of Tourism Eco-Efficiency in the Yangtze River Delta Urban Agglomeration. Environmental Research and Public Health, 185,2577 . and developing countries: the case of carbon dioxide and sulfur dioxide. Journal of Environmental Management, 917, 1580-1592.

Tan, Y., Mao, X., 2020. Assessment of the policy effectiveness of central inspections of environmental protection on improving air quality in China. Journal of Cleaner Production, 28812, 125100.

Tang, M. G., Li, Z., Hu, F. X., Wu, B. J., 2020. How does urban land expansion promote urban eco-efficiency? The mediating effect of sophistication of industrial structure. Journal of Cleaner Production, 272, 122798.

Tong, Y., Zhou, H. F., Jiang, L., 2020. Exploring the transition effects of foreign direct investment on the eco-efficiency of Chinese cities: Based on multi-source data and panel smooth transition regression models. Ecological Indicators, 1212, 107073. direct investment on the eco-efficiency of Chinese cities: based on multi-source data and panel smooth transition regression models. Ecological Indicators, 1212, 107073.

Vural, G., 2021. Analyzing the impacts of economic growth, pollution, technological innovation and trade on renewable energy production in selected Latin 
American countries. Renewable Energy 171, 210-216.

Wang, J. Y., Wang, S. J., Li, S. J., Feng, K. S., 2019. Coupling analysis of urbanization and energy-environment efficiency: evidence from Guangdong province. Applied Energy, 254Nov.15, 113650.1-113650.12.

Wang, M., Feng, C., 2021. The win-win ability of environmental protection and economic development during China's transition. Technological Forecasting and Social Change 166, 120617.

Wang, S., Wang, X. L., Lu, F., Fan, F., 2020. The impact of collaborative innovation on ecological efficiency-empirical research based on China's regions. Technology Analysis and Strategic Management 33, 242-256.

Wang, Z., Feng, C., 2015. Sources of production inefficiency and productivity growth in China: A global data envelopment analysis. Energy Economics, 49may, 380389.

Xue, D., Yue, L., Ahmad, F., Draz, M. U., Chandio, A. A. 2021. Urban ecoefficiency and its influencing factors in western China: fresh evidence from Chinese cities based on the US-SBM. Ecological Indicators, 1271, 107784.

Xue, P. Y., Zhao, Q. L., Sun, H. X., Geng, L. P., Yang, Z. Z., Liu, W. J., 2019. Characteristics of heavy metals in soils and grains of wheat and maize from farmland irrigated with sewage. Environmental Science and Pollution Research 266, 5554-5563. Yang, B., Wang, Z. Q., Zou, L., Zou, L. L., Zhang, H. W., 2021. Exploring the ecoefficiency of cultivated land utilization and its influencing factors in China's Yangtze River Economic Belt, 2001-2018. Journal of Environmental Management, 294, 112939. Yang, Z. J., Zhao, Y., Cao, J., Nielsen, C. P., 2021. Co-benefits of carbon and pollution control policies on air quality and health till 2030 in China. Environment International 152683-693, 106482.

Yasmeen, H., Tan, Q. M., Zameer, H., Tan, J. L., Nawaz, K., 2020. Exploring the impact of technological innovation, environmental regulations and urbanization on ecological efficiency of China in the context of COP21. Journal of Environmental 
Management 274, 111210.

684 multi-level analysis on household and industrial pollution. Science of The Total 685 Environment, 749, 141478.

686 Zhang, J. X., Chang, Y., Zhang, L. X., Li, D., 2018. Do technological innovations 687 promote urban green development? - A spatial econometric analysis of 105 cities in 688 China. Journal of cleaner production 182, 395-403.

689 Zhang, Y. M., Chen, J., Wang, L. Q., Zhao, Y. L., Ou, P., Shi, W. L., 2018. 690 Establishing a health risk assessment for metal speciation in soil-A case study in an 691 industrial area in China. Ecotoxicology and Environmental safety 166, 488-497.

692 Zhou, X. X., Cai, Z. M., Tan, K. H., Zhang, L. L., Song, M. L., 2021. Technological 693 innovation and structural change for economic development in China as an emerging 694 market. Technological Forecasting and Social Change 1671, 120671. 